\title{
Erratum to: Simulation of Space Charge Dynamic in Polyethylene Under DC Continuous Electrical Stress
}

\author{
HAMED BOUKHARI ${ }^{1,2}$ and FATIHA ROGTI ${ }^{1,3}$ \\ 1.-Laboratoire de développement des matériaux semi-conducteur et matériaux diélectrique, \\ Département de Génie Electrique, Université Amar Telidji, Laghouat Route de Ghardaia, BP 37, \\ Laghouat, Algeria. 2.—e-mail: hamedboukha@gmail.com. 3.—e-mail: fatiha_r_2001@yahoo.fr
}

\section{Erratum to: Journal of ELECTRONIC MATERIALS \\ DOI: $10.1007 / \mathbf{s 1 1 6 6 4 - 0 1 6 - 4 7 2 3 - y ~}$}

In the initial online publication Hamed Boukhari's first name and last name were interchanged. It has been corrected in the publication as shown in this erratum. 